activity, or more damage present the effect of radiological damage on physical function decreased. Using the derived linear regression models and the measure of a clinical relevant difference in HAQ-DI a clinical relevant increase in radiological damage for the modified Sharp score was calculated.

Results The clinical relevant increase in radiological damage was estimated to be about 10 or 20 , for a DAS of 1 or 2 respectively. It was dependant on the activity of the disease and amount of existing joint damage.

Conclusion Estimating a clinical relevant increase in radiological progression, using the patient's perspective is possible. A conservative threshold of 10-20 for a clinical relevant increase (Modified Sharp score) can be used as a guideline. These results need replication in other patient cohorts.

\section{THU0172 THE CORRELATION ANALYSIS OF FUNCTIONAL DISABILITY INDEXES WITH DISEASE ACTIVITY DETERMINANTS IN WOMEN WITH ACUTE RHEUMATOID ARTHRITIS}

${ }^{1} \mathrm{M}$ Býrtane, ${ }^{1} \mathrm{~A}$ Hakguder, ${ }^{2} \mathrm{M}$ Eryavuz, ${ }^{1} \mathrm{~S}$ Kokino. ${ }^{1}$ Physical Medicine and Rehabilitation, Trakya University Medical Faculty, Edirne; ${ }^{2}$ Physical Medicine and Rehabilitation, Istanbul Universty Cerrahpasa Medical Faculty, Istanbul, Turkey

\subsection{6/annrheumdis-2001.1074}

Background Rheumatoid arthritis (RA) is a chronic inflammatory disease causing joint deformities and consequent functional disability.

Objectives The aim of this cross-sectional study was to assess the possible correlations between some determinants of (CRP disease activity such as Ritchie articular index (RAI), erytrocyte sedimentation rate (ESR), C-reactive protein) and the functional disability questionnaires in women with acute RA, aged between 50 and 65 .

Methods The functional status of 52 women with acute RA, diagnosed according to modified ARA criteria were assessed by Health Assessment Questionnaire (HAQ) and Lee Functional Index (LFI). Ritchie Articular Index values were determined with joint examination, ESR and CRP with laboratory techniques in blood samples. The relations between these disease activity determinants and functional scores were assessed by correlation analysis.

Results A strong positive correlation was found between two functional indexes $(\mathrm{r}=0.87, \mathrm{p}<0.0001)$. The significant correlations found between ESR, CRP and LFI $(r=0.31, p<0.01 ; r$ $=0.40, \mathrm{p}<0.001$, respectively), were stronger than the positive correlations determined between the same variables and HAQ $(r$ $=0.26, \mathrm{p}<0.05 ; \mathrm{r}=0.29, \mathrm{p}<0.05$, respectively). RAI exhibited stronger correlations with HAQ and LFI when compared with those of laboratory variables with HAQ $(r=0.47, p<$ $0.01 ; \mathrm{r}=0.56, \mathrm{p}<0.001$, respectively).

Conclusion The most related disease activity determinants with examined functional disability levels in women with acute RA were observed to be RAI, CRP and ESH, consecutively. The prediction values of joint symptoms seemed to be more prominent when compared with laboratory variables.

\section{REFERENCES}

1 Jansen $L M$, van Schaardenburg $D$, van Der Horst-Bruinsma IE, Bezemer PD, et al. Predictors of functional status in patients with early rheumatoid arthritis. Ann Rheum Dis. 2000;59(3):223-6

2 McFarlane AC, Brooks PM. Determinants of disability in rheumatoid arthritis. $J$ Rheumatol. 1998;27(1):7-14
3 Smedstad LM, Moum T, Guillemin F, Kvien TK, et al. Correlates of functional disability in early rheumatoid arthritits: a cross-sectional study of 706 patients in four European countries. Br J Rheumatol. 1996;35(8):746-51

\section{THU0173 GENETIC ANTICIPATION IN FAMILIAL RHEUMATOID ARTHRITIS}

EP Sharapova, LI Alexeeva, IA Guseva, SA Finogenova, MY Krylov, EY Samarkina, MA Moshnina, VA Myakotkin. Epidemioilogy and Genetics, Institute of Rheumatology, Moscow, Russia

\subsection{6/annrheumdis-2001.1075}

Background Rheumatoid arthritis (RA) is à systemic inflammatory disease of connective tissue which is characterised by chronic progressing articular lesion and disturbances in immune system. Aetiology of the disease is still unknown. Nevertheless, the role of genetic factors in its determination is confirmed by multiple family and twins studies.

Objectives Òî determine if there is evidence for genetic anticipation in RA in multicase RA pedigrees.

Methods Age at onset and disease severity was compared within 26 parent/offspring pairs with RA.

Results The age at onset of RA was earlier in the offspring than in parents $(26,3 \pm 12,5$ and 45,65 $\pm 14,0$ correspondingly), and this difference is statistically reliable $(\partial<0.01)$. In couples aunts-cousins $(\mathrm{N}=6)$ in mîaå advanced age aunts fall ill (44.Ç \pm 15.9 and $25.0 \pm 9,4$ correspondingly) and the disease onset relating to age is also statistically reliable $(ð<0.02)$. In these multicase RA pedigrees, the offspring had a tendency to more severe disease, despite shorter disease duration and younger age. Conclusion These results suggest genetic anticipation occurs in RA, where the beginning of disease manifestation becomes earlier in the following generation.

\section{THU0174 REACTIVE AMYLOIDOSIS IN PATIENTS WITH RHEUMATOD ARTHRITIS}

${ }^{1} \mathrm{P}$ Wiland, ${ }^{2} \mathrm{R}$ Wojtala, ${ }^{1} \mathrm{~J}$ Szechiñski. ${ }^{1}$ Institute of Rheumatology; ${ }^{2}$ Institute of Pathology Medicine, Railway District Hospital, Wroc $3 a w$, Poland

10.1136/annrheumdis-2001.1076

Background It has been known that reactive (secondary, AA) amyloidosis (RAA) is a major complication of rheumatoid arthritis and amyloidosis is still a main cause of death in rheumatoid arthritis (RA) patients. Diagnosis of amyloidosis is based on Congo red staining of amyloid deposits in tissue biopsies. The safe and simple examination is abdominal fat aspiration biopsy (AFAB).

Objectives The aim of the study was to investigate the positive rate of amyloid deposits in AFAB samples and to clarify whether the presence of amyloid deposits is correlated with the clinical features of patients.

Methods AFAB was performed in patients with established diagnosis of RA referred to our department during the period from 1996 to 2001.

Results Among 103 patients (15 males, 88 females) marked amyloidosis deposits were found in $34(33 \%)$ cases. The incidence of amyloidosis was more frequent in male than female patients (53\% male vs $29 \%$ female). Raised levels of creatinine (>1,3 mg $\%$ ) were found in $27 \%$ patients with amyloidosis and $3 \%$ without amyloidosis; proteinuria respectively in 35\% with positive $\mathrm{AFAB}$ and $13 \%$ with negative $\mathrm{AFAB}$ results. There was no 
difference in both groups according to age, presence of rheumatoid factor, values of erythrocyte sedimentation rate (ESR), Creactive protein (CRP), bacteriuria, presence of erosions in hand and weight. It was found, that patients with proven amyloidosis in AFAB had longer duration of RA (15 years) than patients without amyloidosis (4,5 years). The patients without amyloidosis were more intensively treated with disease-modifying antirheumatic drugs (DMARDs) than patients with amyloidosis what was especially distinct in patients with duration of RA at least ten years; simultaneously time of corticosteroid treatment was longer in patients with amyloidosis.

Conclusion The observed frequency of amyloidosis was very high when compared with results from other countries. In our opinion the reason probably lies in fact that RA patients were treated only with corticosteroids instead of intensive use of DMARDs. In addition AFAB gives a possibility to find the early phase of amyloidosis before occurrence of overt clinical symptoms like proteinuria or renal insufficiency.

\section{THU0175 THE CELECOXIB LONG-TERM ARTHRITIS SAFETY STUDY (CLASS): CELECOXIB IS ASSOCIATED WITH LESS RENAL TOXICITY COMPARED TO CONVENTIONAL NONSTEROIDAL ANTI-INFLAMMATORY DRUGS (NSAIDS)}

${ }^{1} \mathrm{~A}$ Whelton, On Behalf of the CLASS Investigators ${ }^{2}$, On Behalf of the CLASS Investigators ${ }^{3}$. 'Universal Clinical Research Center, Inc., Hunt Valley; ${ }^{2} J o h n s$ Hopkins Medical School, Baltimore; ${ }^{3}$ Pharmacia Corporation, Skokie, USA

\subsection{6/annrheumdis-2001.1077}

\section{Background}

Objectives Conventional NSAIDs, which nonselectively inhibit cyclooxygenase (COX)-1 and COX-2, are associated with deleterious effects on renal function such as reductions in glomerular filtration rate and sodium retention. Celecoxib specifically inhibits COX-2. Such specific inhibition raises the possibility that the incidence of renal toxicity vs conventional NSAIDs may be reduced.

Methods In a randomised, double-blind trial with exposures of up to 15 months, 7968 patients with osteoarthritis (OA) $(\mathrm{n}=$ 5746) or rheumatoid arthritis (RA) $(\mathrm{n}=2183)$ were randomised to receive supratherapeutic doses of celecoxib (400 mg BID; $\mathrm{n}=$ $3,987)$ vs ordinary therapeutic doses of conventional NSAIDs: ibuprofen (800 mg TID; $\mathrm{n}=1996$ ) or diclofenac (75 mg BID; $\mathrm{n}$ $=1985)$.

Results Fewer celecoxib-treated patients experienced renal toxicity compared to patients treated with NSAIDs (see Table 1; "p $<0.05$ vs celecoxib, **serum creatinine levels above $2 \mathrm{mg} / \mathrm{dL}$ and/or BUN values above $40 \mathrm{mg} / \mathrm{dL}$ ).

\begin{tabular}{llll} 
Abstract THU0175 Table 1 & \\
\hline & $\begin{array}{l}\text { Celecoxib ( } \mathrm{n}= \\
\text { 3987) }\end{array}$ & $\begin{array}{l}\text { Incidence (\% of } \\
\text { patients) } \\
\text { Diclofenac }(\mathrm{n}=\end{array}$ & $\begin{array}{l}\text { Ibuprofen ( } \mathrm{n}= \\
1986)\end{array}$ \\
& & $1985)$ & \\
\hline Peripheral oedema & 3.7 & 3.5 & $5.2^{*}$ \\
Generalised oedema & 0.5 & 0.6 & $1.0^{*}$ \\
Hypertension (HTN) & 2.0 & 2.0 & $3.1^{*}$ \\
Aggravated HTN & 0.8 & 0.6 & 1.2 \\
Creatinine and/or BUN & 1.3 & $2.1^{*}$ & 1.4 \\
elevation* * & & & \\
\hline
\end{tabular}

Conclusion Celecoxib at supratherapeutic doses was associated with a lower incidence of renal toxicity compared to conventional NSAIDs at ordinary therapeutic doses.

Sponsored by Pharmacia Corporation and Pfizer, Inc.

\section{THU0176 CELECOXIB IS ASSOCIATED WITH SIGNIFICANT ACR50/ 70 RESPONSES IN RHEUMATOID ARTHRITIS (RA)}

${ }^{1}$ EA Tindall, On Behalf of the 024 Investigators ${ }^{2}$. 'Department of Medicine, Oregon Health Sciences University, Portland; ${ }^{2}$ Research and Development, Pharmacia Corporation, Skokie, USA

10.1136/annrheumdis-2001.1078

\section{Background}

Objectives Celecoxib, a specific cyclooxygenase (COX)-2 inhibitor, has been shown to improve the signs and symptoms of RA. Because of the safety and tolerability of this agent, celecoxib administration is more sustainable, potentially producing longterm decreases in disease activity.

Methods The ability of celecoxib to induce responses at the ACR20, ACR50, and ACR70 levels was determined in a pooled analysis of two placebo- and active-comparator controlled trials. In addition, radiographic data from a long-term open label safety trial were analysed for the effect of celecoxib on radiographic evidence of disease progression using the Sharp score and Sharp count. Dose titration was allowed during this trial.

Results Celecoxib induced significant improvement compared to placebo at the ACR20, ACR50, and ACR70 levels at 12 weeks during the controlled trials (see Table 1 for $\%$ of responders, * $p$ $<0.05$ vs placebo). Prior to entry to the long-term open label trial, the average changes in the Sharp score and count were 2.76 (95\% confidence interval [CI] 0.68-4.84) units/year and 1.15 (95\% CI 0.10-2.19) units/year. After entry, the average changes in the Sharp score and count were 1.72 (95\% CI 1.04$2.39)$ units/year and $0.63(0.40-0.87)$ units/year, with an average duration of follow-up of approximately 1 year.

\begin{tabular}{|c|c|c|c|c|}
\hline & Placebo & $\begin{array}{l}\text { Celecoxib } \\
100 \mathrm{mg} \text { BID }\end{array}$ & $\begin{array}{l}\text { Celecoxib } \\
200 \mathrm{mg} \text { BID }\end{array}$ & $\begin{array}{l}\text { Naproxen } \\
500 \mathrm{mg} \text { BID }\end{array}$ \\
\hline \multicolumn{5}{|c|}{ Response Level } \\
\hline ACR20 & $26 \%$ & $34 \% *$ & $41 \% *$ & $38 \% *$ \\
\hline ACR50 & $5 \%$ & $7 \%$ & $12 \%$ * & $11 \% *$ \\
\hline ACR70 & $1 \%$ & $1 \%$ & $3 \%$ * & $1 \%$ \\
\hline
\end{tabular}

Conclusion Combined with the safety and tolerability data derived from recent studies, these data suggest that celecoxib has the potential to modify disease activity in RA with long-term use in addition to providing symptomatic benefits over shorter durations.

Sponsored by Pharmacia Corporation and Pfizer, Inc. 